\title{
Regular Exposure to Cowbells Affects the Behavioral Reactivity to a Noise Stimulus in Dairy Cows
}

\author{
Julia Johns ${ }^{1,2}$, Sophie Masneuf ${ }^{2,3}$, Antonia Patt ${ }^{2,4}$ and Edna Hillmann ${ }^{2,5 *}$ \\ ${ }^{1}$ Faculty of Organic Agricultural Sciences, Farm Animal Behavior and Husbandry Section, University of Kassel, \\ Witzenhausen, Germany, ${ }^{2}$ Ethology and Animal Welfare Unit, Department of Environmental Systems Science, Institute \\ of Agricultural Sciences, ETH Zurich, Zurich, Switzerland, ${ }^{3}$ Department of Neurology, University Hospital Zurich, Zurich, \\ Switzerland, ${ }^{4}$ Institute of Animal Welfare and Animal Husbandry, Friedrich-Loeffler-Institut, Federal Research Institute \\ for Animal Health, Celle, Germany, ${ }^{5}$ Animal Husbandry, Albrecht Daniel Thaer-Institute of Agricultural and Horticultural \\ Sciences, Humboldt-Universität zu Berlin, Berlin, Germany
}

\section{OPEN ACCESS}

Edited by: Laura Ann Boyle,

Teagasc, The Irish Agriculture and Food Development Authority, Ireland

Reviewed by: Courtney L. Daigle, Texas A\&M University, United States Renate Luise Doerfler, Technische Universität

München, Germany

*Correspondence: Edna Hillmann edna.hillmann@hu-berlin.de

Specialty section: This article was submitted to Animal Behavior and Welfare, a section of the journal Frontiers in Veterinary Science

Received: 04 May 2017 Accepted: 05 September 2017 Published: 29 September 2017

Citation:

Johns J, Masneuf S, Patt A and Hillmann E (2017) Regular Exposure to Cowbells Affects the Behavioral Reactivity to a Noise Stimulus in Dairy Cows.

Front. Vet. Sci. 4:153. doi: 10.3389/fvets.2017.00153
In alpine regions, cows are often equipped with bells during pasture season to ensure that farmers can locate them. Constant exposure to the chime of a bell may affect cows' acoustic perception in general. The aim of this study is to test whether routine bell exposure affects the reactivity to a noise stimulus and might be associated with hearing impairment in cows. For the assessment, behavioral and cardiac indicators were used as indirect measures of hearing capacity. Cows that were either used to wearing a bell or not were exposed to a playback of low and high amplitude (=varying loudness). In addition, we tested whether wearing earplugs, mimicking hearing impairment, reduced the cows' reactivity toward the playback. On 24 farms, half of them routinely using cowbells, 96 Brown Swiss cows were tested in a $2 \times 2$ factorial cross-over design (65 or $85 \mathrm{~dB}$, without or with earplugs) in a balanced order. The effects of bell experience, amplitude, and earplugs on the latency to the first behavioral and cardiac response to a 5-s playback were analyzed using linear mixed-effects models, considering dependencies within the data set. Cows reacted faster without earplugs and when they were exposed to $85 \mathrm{~dB}$ compared with $65 \mathrm{~dB}$. The proportion of cows leaving the feeding rack after onset of the playback was reduced by bell experience and earplugs and was increased when exposed to $85 \mathrm{~dB}$ compared with $65 \mathrm{~dB}$. Exposure without earplugs to $85 \mathrm{~dB}$ but not to $65 \mathrm{~dB}$ increased heart rate. Heart rate and heart rate variability indicated increased sympathetic activation during the exposure to $85 \mathrm{~dB}$ compared with $65 \mathrm{~dB}$. In general, behavioral and cardiac indicators did not indicate severe hearing impairment due to routine bell exposure. The $85-\mathrm{dB}$ stimulus increased arousal and avoidance compared with the 65-dB stimulus, with bell experience and earplugs leading to a general decrease in avoidance of the stimulus. This may reflect an altered acoustic perception of the playback stimulus in dairy cows that are routinely exposed to bells.

Keywords: avoidance, behavior, cattle, earplug, noise, playback

\section{INTRODUCTION}

In alpine regions, cows are often equipped with a bell throughout the summer season to ensure that farmers can locate their animals on the wide alpine pastures, many areas that are obstructed from view. The chime of these cowbells is characterized by high and varying amplitudes from 90 to $113 \mathrm{~dB}$ at a distance of $20 \mathrm{~cm}$, the approximated distance between the bell and the cows' ears (1). Goats 
have been found to show higher behavioral arousal when being exposed to the playback of a bell compared to the playback of a uniform sinusoidal sound, indicating that the bell sound might be more aversive to goats than the uniform sound. With repeated exposure, goats habituated to both stimuli (2).

So far, little research has been conducted investigating the effect of noise on the hearing capacities of animals. Kenneled dogs that were constantly exposed to noise between 100 and $108 \mathrm{~dB}$ for 6 months developed hearing loss as indicated by measurements of the auditory brainstem response (ABR) (3). In mice, $A B R$ recordings showed that a single exposure to noise of $100 \mathrm{~dB}$ for $2 \mathrm{~h}$ induced temporary hearing loss (4), and an exposure to noise of $110 \mathrm{~dB}$ for 60 min even induced permanent hearing loss (5).

Noise-induced hearing loss is one of the most common causes of exogenously acquired sensorineural hearing loss in adult humans (6). Although anatomic differences among mammal species lead to differences in hearing capacities (7), the basic physiologic processes underlying the detection and sensation of sound are essentially identical between humans, dogs, cattle, and mice (8-11). Considering that cows can hear sounds between $23 \mathrm{~Hz}$ and $35 \mathrm{kHz}$, with the highest sensitivity at $8 \mathrm{kHz}$, and are able to detect sounds at $-11 \mathrm{~dB}$, i.e., amplitudes the human ear cannot detect (11), the continuous exposure to bells during pasturing season might impair the cows' hearing capacity.

Behavioral indicators such as the acoustic startle response $(12-15)$ or avoidance reactions $(16,17)$ have been used as an indirect but non-invasive test of hearing capacity in earlier studies. The acoustic startle response is an electromyographic response, which in rodents is elicited by stimuli with an amplitude of more than $80 \mathrm{~dB}(18,19)$, and the latency is very short [5-10 ms for the electromyographically measured response in different muscles (20-22)]. Behaviorally, a startle response is defined as a cross-species response to an intense and abrupt stimulus (23) and as any first reaction of any part of the body, such as body movements, movements of limbs and facial movements, or any first behavioral reaction to sound stimulation (24). Therefore, the latency to the first behavioral reaction, e.g., sudden head movements in response to an acoustic stimulus can be used as a proxy for the induction of a startle response. In addition, avoidance reactions in response to an acoustic stimulus, e.g., increasing the distance between the source and oneself, indicate that the stimulus is perceived as aversive by the animals (25-27).

In addition, cardiac parameters such as heart rate and heart rate variability can be used to assess arousal induced by noise $(2,28)$. If cardiac parameters indicate an arousal due to noise exposure, it can be assumed that the animal perceives the noise as aversive (23). Noise exposure is often accompanied by an increase of heart rate in humans $(29,30)$. Lee et al. (31) evaluated instant responses of the autonomic nervous system to shortduration noises using heart rate variability analysis. The results indicated that, compared with background noise of $38 \mathrm{~dB}$, exposure to noise between 50 and $80 \mathrm{~dB}$ increased sympathetic activity as indicated by a higher ratio of low-frequency (LF) to high-frequency (HF) spectral power. For humans, "hazardous" noise is defined as sounds that exceed $85 \mathrm{~dB}$ over a typical 8-h workday $(32,33)$. It has been shown that constant exposure to such hazardous noise can result in irreversible hearing loss and that even a single intense sound event can cause hearing loss and tinnitus $(32,33)$.

A widespread solution used to protect humans and also horses from noise exposure by using hearing protection devices such as earplugs $(34,35)$. Commercially available earplugs for horses are made of memory foam (35). In cattle, acoustic earphones were inserted into the ear canal and were held in position with either silicone earplugs or earplugs of compressible foam while measuring brainstem auditory evoked potentials (BAEPs) (36-38). Such earplugs occlude the ear canal and attenuate background noise.

Although some studies on the general hearing capacity of cows are available, to our knowledge, no studies exist on hearing capacities of cows that have been exposed to noise in general. Bells seem to be a relevant noise factor for cows considering that cows are exposed routinely and for a longer period of time to the chime of bells (1). The aim of this study is to test whether routine bell exposure affects the reactivity to a noise stimulus and be associated with hearing impairment in cows. Behavioral and cardiac indicators were used as indirect measures for the assessment of cows' hearing capacity. Thus, we examined the reactivity toward noise of low $(65 \mathrm{~dB})$ and high $(85 \mathrm{~dB})$ amplitude in bell-experienced and bell-inexperienced cows on 24 Swiss dairy farms. We additionally tested whether mimicking hearing impairment using earplugs would reduce the reactivity to the sounds. We hypothesized that cows that had been exposed regularly to a bell on alpine pastures (bell-experienced cows) would show reduced reactivity toward these sounds (increased latency of the first behavioral reaction, reduced avoidance and heart rate, and increased heart rate variability) contrarily with cows that were only equipped with a bell as heifers or never before (bell-inexperienced cows). Contrary, we expected that cows would show increased reactivity in response to a stimulus of high amplitude (decreased latency of the first behavioral reaction, increased avoidance and heart rate, and reduced heart rate variability) compared to a stimulus of low amplitude. Further, we expected that cows without earplugs would also show increased reactivity toward these sounds (decreased latency of the first behavioral reaction, increased avoidance and heart rate, and reduced heart rate variability) compared to cows with earplugs. Altogether, if earplugs do not diminish the reaction of a given cow, this might be an indicator of either a low-reactive animal, well habituated to noise or hearing impairment.

\section{ANIMALS, MATERIALS, AND METHODS}

Ethical approval to conduct the study was obtained from the Zurich Cantonal Veterinary Office, Switzerland (approval No. 77/2012).

\section{Animals, Housing, and Management}

The study was performed between September and November 2013 on 24 Swiss farms, with 96 multiparous Brown Swiss cows that were between 3 and 10 years of age. The owners of the cows gave permission to conduct the study on their farms. The size of the farms varied between 8 and 100 animals. On each farm, four 
experimental cows were selected randomly. On 12 farms, cows were used to wearing a bell either every year for 4-5 months during the summer season or all year round (48 cows on 12 farms, "experienced"). On the other 12 farms, cows had no or very little experience with wearing a bell, having either never worn a bell before or only once for 4-5 months when they were 1 year old ( 48 cows on 12 farms, "inexperienced"). On all 24 farms, cows were kept in cubicle housing systems with a feeding rack and headlocks. All cows were familiar with being locked in the feeding rack during feeding. They were fed with hay, fresh grass or a mixed ration of hay, corn, and grass silage. Feed and water were provided ad libitum. The cows were milked twice a day.

\section{Test Area within Barn}

The experiment was carried out at the feeding rack of each farm during the course of 1 day. A 5-m section of the feeding rack served as test area for the experiment. During the experiment, only the four experimental cows had access to this area, one cow at a time. To record the animals' behavior, a video camera with an integrated microphone (Canon ${ }^{\circledR}$ Legria FS 200 digital camera) was mounted on a tripod and positioned in front of the separated feeding rack area (Figure 1). The acoustic stimulus was transmitted via two loudspeakers $\left(\right.$ Edifier $^{\circledR}$ S2000v, Edifier International, Hong Kong, China) that were positioned on the floor next to the camera. The loudspeakers, the tripod, and cables were hidden behind a visual cover of white fabric (Figure 1) and placed on a board (approximately $1.5 \mathrm{~m} \times 1.5 \mathrm{~m}$ ). The front edge of the board with the loudspeakers was placed in the feeding alley at a distance of $2.15 \mathrm{~m}$ from the feeding rack to ensure that the intended amplitude reached the cows' ears.

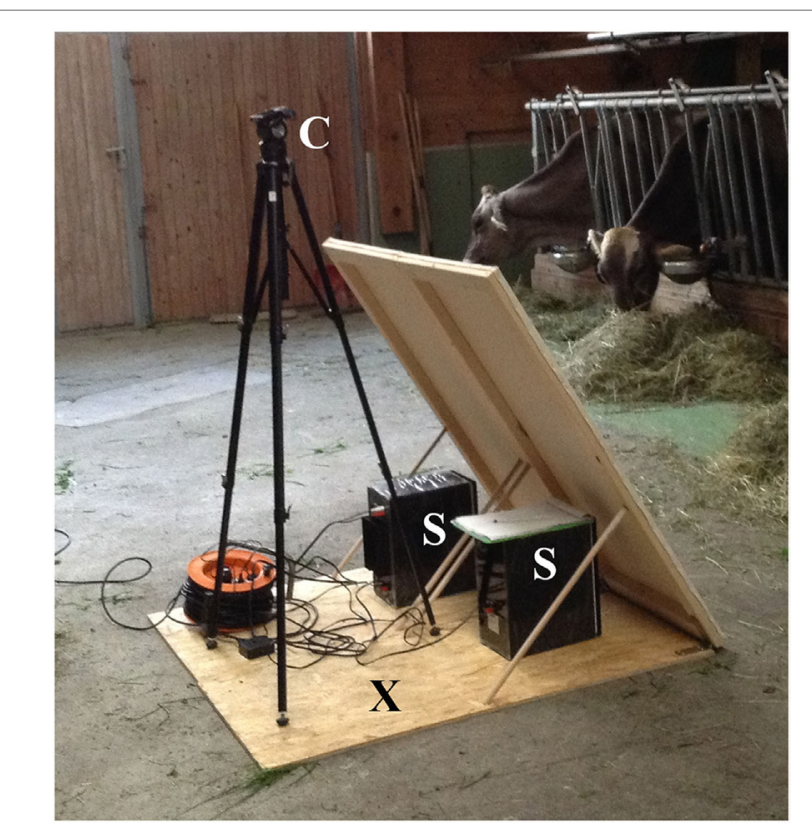

FIGURE 1 | Technical equipment. Technical equipment behind a visual cover of white fabric. C, camera; S, speakers; $\mathrm{X}$, experimenters were hidden behind the visual cover during playback.

\section{Acoustic Stimulus}

Each cow was exposed to a pink noise stimulus broadcast four times for $5 \mathrm{~s}$ in a $2 \times 2$ factorial design: each cow was tested with and without earplugs and at 65 (A-weighting scale, A) and $85 \mathrm{~dB}$ (A) (Figure 2; each amplitude with two phases: without and with earplugs), i.e., each of the bell-experienced and bellinexperienced cows were exposed to each amplitude (65 and $85 \mathrm{~dB}$ ) twice, once with and once without earplugs ( 4 trials per cow, see Experimental Procedure). The A-weighting scale assigns low weights to the LF tones, to which the human ear and the ears of some animals are less sensitive, and high weights to the HF tones, to which humans are more sensitive (39).

Pink noise is characterized by uniformly distributed energy throughout the range of human hearing, approximately $20 \mathrm{~Hz}-20 \mathrm{kHz}$. Most people perceive pink noise as having uniform spectral power density, i.e., the same loudness at all frequencies (40). The noise stimulus was automatically generated by a Tone Generator Prov1.0.8 (Performance Audio ${ }^{\circledR}$ ) for iPhone ${ }^{\circledR}$. We chose the pink noise for three reasons: first, it has no biologic relevance for the cows, and therefore, the reactions to the acoustic stimuli were mostly likely limited to the perception of the acoustic stimuli per se. Second, it contains all frequencies from $20 \mathrm{~Hz}$ to $20 \mathrm{kHz}$ at the same amplitude and should thus match the cows' (potential) hearing capacity. Third, it was a novel acoustic stimulus for all cows, and none of them was ever exposed to it before. The volume of the playback was set at a level that ensured an amplitude of either 65 or $85 \mathrm{~dB}(\mathrm{~A})$ at the feeding rack at approximately $60 \mathrm{~cm}$ above the floor (i.e., the estimated position of the cows' heads when feeding). The amplitude was measured with a precision noise level measuring instrument with integrated long-term storage (SoundTest-Master, Laserliner $^{\circledR}$, Umarex GmbH \& Co. KG, Arnsberg, Germany). The background noises at the farms measured before the start of the experiments ranged from 40 to $60 \mathrm{~dB}(\mathrm{~A})$.

\section{Experimental Procedure}

In the morning around 8 O'clock, the visual cover of white fabric with all technical equipment was set up. Before the start of the experiment, the four experimental cows were habituated to the technical equipment (Figure 1), the thorax belt to measure

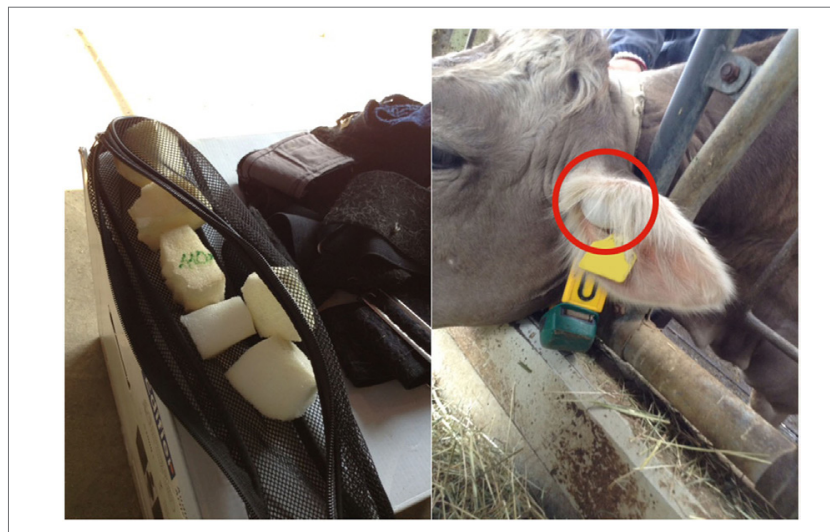

FIGURE 2 | Earplugs. Cow with earplug $(70 \mathrm{~mm} \times 40 \mathrm{~mm} \times 40 \mathrm{~mm})$ made of memory foam (left) in the ear canal (right). 
heartbeat parameters (see Heartbeat Measurements) and the earplugs (Figure 2). Each experimental cow was exposed to the pink noise stimulus in four trials (Figure 3). The order in which the cows were tested was chosen randomly before the start of the experiment. To reduce handling of the cows, the two playbacks during which cows were equipped with earplugs were tested in consecutive trials. Thus, each cow was equipped with the earplugs only once during the experiment with the order of phases and amplitudes chosen randomly for each animal.

On each farm, the four experimental cows were led to the separated 5-m section of the feeding rack, restrained in the headlocks (for feeding), and fitted with a thorax belt. Then, they were habituated to the earplugs. The earplugs $(70 \mathrm{~mm} \times 40 \mathrm{~mm} \times 40 \mathrm{~mm}$; Figure 2) were made of memory foam (polyurethane with additional non-toxic chemicals increasing its viscosity and density; Vibraplast $\mathrm{AG}^{\circledR}$, Aadorf, Switzerland). Earplugs were compressed and placed into the ear canal during feeding, where they expanded and plugged the ear canal. To avoid experimental cows being irritated by a sudden impairment of hearing, the first earplug was positioned into the left ear for $15 \mathrm{~min}$ before the second earplug was placed into the right ear. Experimental cows were left undisturbed for $30 \mathrm{~min}$ with both thorax belt and earplugs in place. During these $30 \mathrm{~min}$, the two earplugs had to remain in position for at least $15 \mathrm{~min}$. If the animal shook its head resulting in the loss of an earplug, the earplug was repositioned. During the first $15 \mathrm{~min}$, the first earplug had to be repositioned 1.3 times (minimum 1 and maximum 6 times), and during the following $30 \mathrm{~min}$, an earplug had to be repositioned 1.9 times (minimum 1 and maximum 7 times). At the end of the habituation phase, all experimental cows accepted the earplugs and continued to feed calmly. After the habituation phase, the earplugs were removed, and the experimental cows were allowed to rejoin the herd for $1 \mathrm{~h}$. To ensure that experimental cows were motivated to feed, cows had no access to feed while rejoining the herd.

After the 1-h break, experimental cows were individually led into the separated area of the feeding rack, restrained in the headlocks, and fitted with the earplugs depending on stimulus order (Figure 3). To avoid exposure to the acoustic stimuli prior to testing, the other experimental cows were either separated in an outdoor paddock ( $n=11$ farms) or fitted with earplugs and led to the farthest part of the stable ( $n=13$ farms).

A handful of concentrate was sprinkled on the usual feed during trials to enhance feeding motivation of the experimental cow. As soon as the experimental cow was feeding calmly for at least $1 \mathrm{~min}$, the headlocks were carefully opened by the second experimenter, and the playback was switched on for $5 \mathrm{~s}(20 \pm 3 \mathrm{~s}$ after opening the headlocks). Start and stop of the playback were controlled manually by the experimenter using a mobile phone (iPhone $4 \mathrm{~s}^{\circledR}$, Apple Inc.). After the end of the playback, behavioral observations and heartbeat measurements continued for 2 more minutes (playback $+2 \mathrm{~min}=$ trial). Each experimental cow was tested in all four trials in one session. When the session was finished, the thorax belt (and earplugs, depending on phase order) was removed, and the cow was allowed to rejoin the herd. If a cow did not start feeding within 1 min after offering the concentrate, no playback was conducted, and another experimental cow was tested.

\section{Behavior}

Behavioral analyses were conducted by two different people (person 1 analyzed the latency to the first reaction, and person 2 analyzed avoidance) who had not participated in the conduct of the experiments. They did not know the farms and were not aware of the aim of the study. However, as they needed to record the behaviors related to the start of the playback, they were aware that acoustic stimuli were involved but were blind to the bell experience of the animals, the amplitude, or if the animals were equipped with earplugs.

In addition, to test intraobserver reliability for the assessment of latency to the first reaction, person 1 assessed 96 trials twice.

\section{Latency to the First Reaction}

The latency to the first reaction was described as time (seconds) it took the experimental cows from the onset of the playback

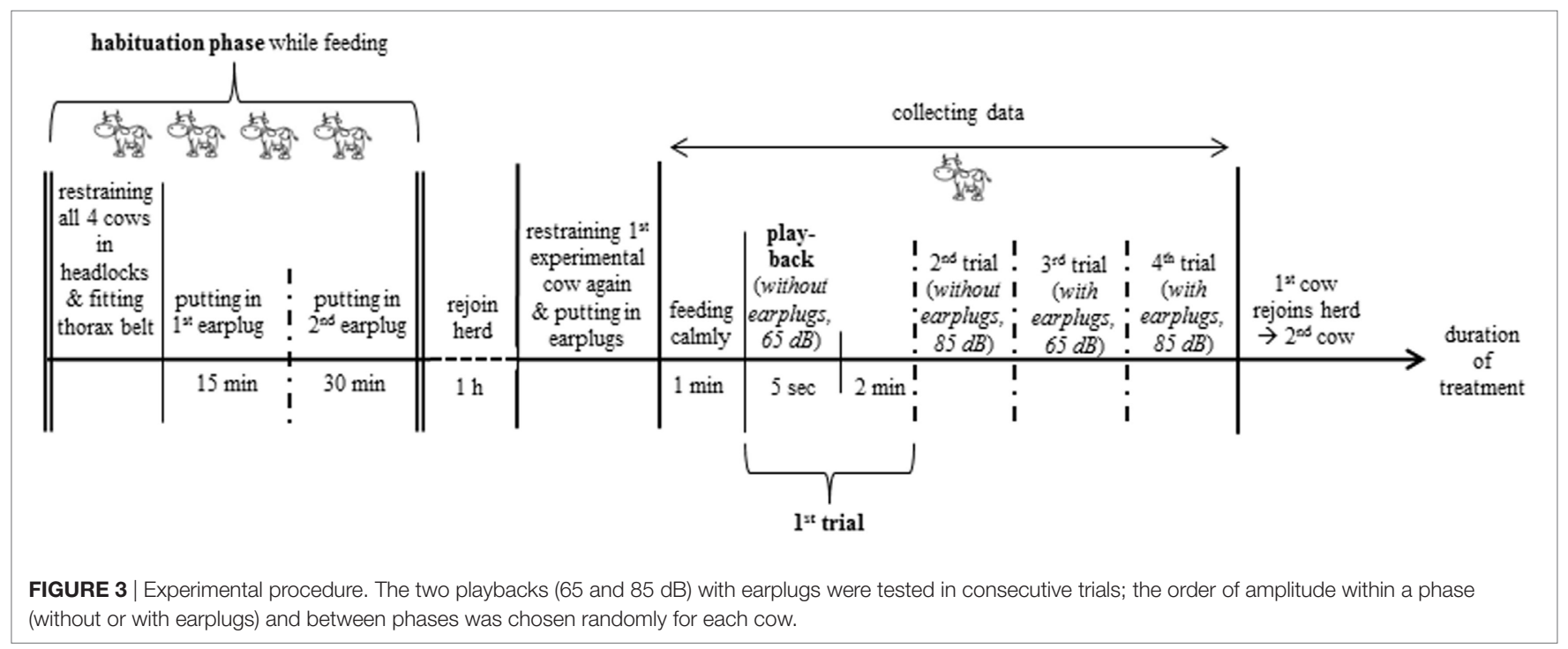


to react with a clearly visible change of the ear posture, pausing (cow stopped her current behavior and froze shortly), or a sudden head movement (cow stopped feeding and raised its head quickly). The latency to the first reaction was analyzed in slow motion $(0.5 \times$ real time $)$ from video using VLC media player $^{\circledR}$ (version 2.2.4 Weatherwax, VideoLAN, Paris, France) and a stopwatch for Smartphone Shift5.1 ${ }^{\circledR}$ (Android version 5.1, SHIFT GmbH, Falkenberg, Germany) for $15 \mathrm{~s}$ after onset of the playback.

\section{Avoidance}

An avoidance reaction to the playback was recorded whenever a cow left the feeding rack (completely withdrawing the head from the feeding rack) within $60 \mathrm{~s}$ after onset of the playback using INTERACT $^{\circledR}$ (Mangold International $\mathrm{GmbH}$, version 9.0.7, Arnstorf, Germany). A duration of $60 \mathrm{~s}$ (=5 s playback $+55 \mathrm{~s}$ ) as a time window that may reflect a response to the playback and not to any other stimuli, e.g., environmental sounds was considered.

\section{Heartbeat Measurements}

Heartbeat measurements were recorded using Polar ${ }^{\circledR}$ Equine (Polar ${ }^{\circledR}$ Elektro Europe BV, Zug, Switzerland), allowing a noninvasive measurement of heartbeats $(41,42)$. To increase the electrode-skin contact, electrode gel (Anandic Medical Systems AG/SA, Feuerthalen, Switzerland) was used. A thorax belt with two integrated electrodes was fixed around the torso directly behind the forelegs. One electrode was positioned ventrally on the left side of the sternum and the other one at a given distance by the thorax belt on the left thoracic wall. A receiver for recording the data was placed between the two electrodes. The thorax belt was additionally protected by an elastic belt of about $5 \mathrm{~cm}$ width. The heartbeat was recorded for $1 \mathrm{~min}$ of continuous feeding before the playback started, during the playback (5 s), and 2 min after the playback. Data were downloaded onto a computer via a base station using Bluetooth (Polar ${ }^{\circledR}$ Team $^{2}$ Pro, version 1.3.0.3).

Analysis of cardiac data was carried out using the programs Polar $^{\circledR}$ ProTrainer 5 Equine Edition (version 5.35.161, (C) Polar Electro Europe AG, Zug, Switzerland) and R 3.2.3 (43). Root mean square of successive differences (RMSSD) of heartbeats reflects changes in the vagosympathetic balance that are vagally mediated (42) and represents parasympathetic activity, whereas standard deviation of heartbeats (SDNN) is a more complex parameter reflecting vagal and sympathetic activation $(42,44)$. The spectral measures HF band and LF band are highly correlated with the time domain-related measures RMSSD and SDNN, respectively $(45,46)$. Consequently, the ratio between RMSSD and SDNN can be used as an indicator of changes of the vagosympathetic balance in the organism (47-49), similar to the ratio of HF and LF (44). An increased ratio between RMSSD and SDNN indicates that vagosympathetic balance is more shifted toward parasympathetic activation, whereas a lower ratio indicates a shift toward sympathetic activation (49).

Automatic correction of the tachograms was carried out using the correction routines included in the Polar ${ }^{\circledR}$ software
(Polar ${ }^{\circledR}$ ProTrainer 5 Equine Edition, version 5.35.161). Data with an error rate of more than 5\% were excluded from the analysis according to the studies by Hagen et al. and Gygax et al. $(46,50)$. In addition, data of one cow were excluded from analysis due to extremely high heart rate regardless of experimental treatment. This led to the exclusion of 286 trials and a remaining sample size of 98 trials.

The number of $\mathrm{R}-\mathrm{R}$ intervals [heart rate in beats per minute (bpm)], the RMSSD (ms) and the ratio between RMSSD and SDNN (RMSSD/SDNN) were calculated. The 1 min preceding the playback and the first minute of the trial were both divided into first (0-20 s), middle (21-40 s), and last (41-60 s) $20 \mathrm{~s}$. The middle $20 \mathrm{~s}$ of the minute preceding the playback was then chosen as reference value for heartbeat parameters. This reference time window was compared with the first time window (0-20 s) after start of the playback (trial value) by calculating the ratios of heart rate (bpm), RMSSD (ms), and RMSSD/SDNN between reference and trial value.

\section{Data Analysis}

The experimental design resulted in a sample size of 384 trials (i.e., 24 farms $\times 4$ experimental cows $\times 4$ trials). However, five cows older than 10 years were excluded from data analysis to avoid the interference of age-dependent hearing impairment (presbycusis) with experimental treatments. One cow had to be excluded from data analysis due to technical problems and another cow due to not feeding at all. In eight trials (five cows on five farms), cows did not start feeding again after a playback exposure. In these cases, we had to quit the session. All these cows had no or very little experience with wearing a bell. Technical problems with video recording occurred in another seven trials. Thus, the total sample size was 89 cows on 24 farms in 341 trials.

Statistical analyses were performed in $\mathrm{R} 3.3 .1$ and 3.3.2 ( $\mathrm{R}$ Core Team 2016, 43). We used the agreement package (51) to check the intraobserver agreement concerning the latency to the first reaction. To adequately reflect dependencies in the experimental design (nesting, repeated measurements), linear mixed-effects models were used to evaluate the latency to the first reaction and heartbeat measurements with the lmer methods from "lme4" and "lmerTest" packages, respectively (52). The occurrence of leaving the feeding rack was analyzed using a generalized linear mixed-effects model [glmer method from package "lme4" (53)]. Here, we used odds ratios [exponential function of the regression coefficient associated with a oneunit increase in the exposure (54)] to additionally quantify the effect sizes.

Full models consisted of the fixed-effects "bell experience" (factor with two levels: experienced, inexperienced), "earplugs" (factor with two levels: with, without), and "amplitude" (factor with two levels: 65 and $85 \mathrm{~dB}$ ) and all possible interactions. Models were reduced in a stepwise backward procedure. $P>0.05$ was used as criterion for exclusion of non-significant interactions. $P$ values were calculated based on likelihood ratio tests. Trial nested in individual identity nested in farm served as random effects. To satisfy model assumptions, heartbeat parameters were $\log$ transformed. 


\section{RESULTS}

In the figures, descriptive data and model estimations are shown; in the text, model estimations and odds ratios were used to interpret the results.

\section{Latency to the First Reaction}

The intraobserver agreement for the assessment of the latency to the first reaction was good, with a concordance coefficient of 0.91 .

As expected, cows reacted faster when exposed to the $85-\mathrm{dB}$ stimulus compared with the $65-\mathrm{dB}$ stimulus $\left(F_{1,212.1}=56.65\right.$, $P<0.001)$ and slower when equipped with earplugs $\left(F_{1,214.6}=65.05\right.$, $P<0.001)$. Bell experience did not affect the latency to the first reaction $\left(F_{1,24.5}=0.5, P=0.486\right.$, Figure 4$)$.

\section{Avoidance}

The probability for a cow to leave the feeding rack within $60 \mathrm{~s}$ after exposure to the sound stimulus was strongly increased when cows were exposed to $85 \mathrm{~dB}$ compared with $65 \mathrm{~dB}$ (odds ratio $=3.20$; $\chi^{2}=17.29 ; P<0.001$; Figure 5). Similarly, the probability to leave the feeding rack was reduced when wearing earplugs (odds ratio $=0.30 ; \chi^{2}=17.63 ; P<0.001$; Figure 5) and when cows were bell experienced (odds ratio $=0.33 ; \chi^{2}=4.92 ; P=0.027$; Figure 5).

\section{Heartbeat Measurements}

In the description of the results of heartbeat measurements, a ratio $>1$ indicates that the trial value was greater than the reference value, and vice versa for a ratio $<1$.

The mean absolute heart rate was 78.9 bpm (minimum: $54 \mathrm{bpm}$, maximum: $180 \mathrm{bpm}$ ) in the minute before and $79.5 \mathrm{bpm}$ (minimum: $54 \mathrm{bpm}$, maximum: $180 \mathrm{bpm}$ ) in the minute after playback exposure and showed a large interindividual variability. When cows were exposed to $85 \mathrm{~dB}$ without earplugs, heart rate during the first $20 \mathrm{~s}$ after onset of the playback was increased compared with the baseline heart rate (amplitude $\times$ earplugs: $F_{1,100.1}=3.99 ; P=0.048$; Figure 6A). We found no effect of bell experience $\left(F_{1,16.8}=0.44 ; P=0.515\right)$ on heart rate response.

The RMSSD ratio following the playback at $85 \mathrm{~dB}$ was increased compared with the RMSSD ratio following the playback at $65 \mathrm{~dB}$ $\left(F_{1,102.8}=5.58 ; P=0.020\right)$. Further, RMSSD ratio was lower when wearing earplugs than when not wearing earplugs $\left(F_{1,48.4}=6.22\right.$; $P=0.016)$. We found no effect of bell experience $\left(F_{1,56.0}=0.09\right.$; $P=0.769$ ) on RMSSD response (Figure 6B).

The RMSSD/SDNN ratio was reduced when cows were exposed to $85 \mathrm{~dB}$ compared with $65 \mathrm{~dB}\left(F_{1,107.2}=13.45 ; P<0.001\right)$, and it was slightly increased by earplugs $\left(F_{1,53.2}=3.27 ; P=0.076\right.$;

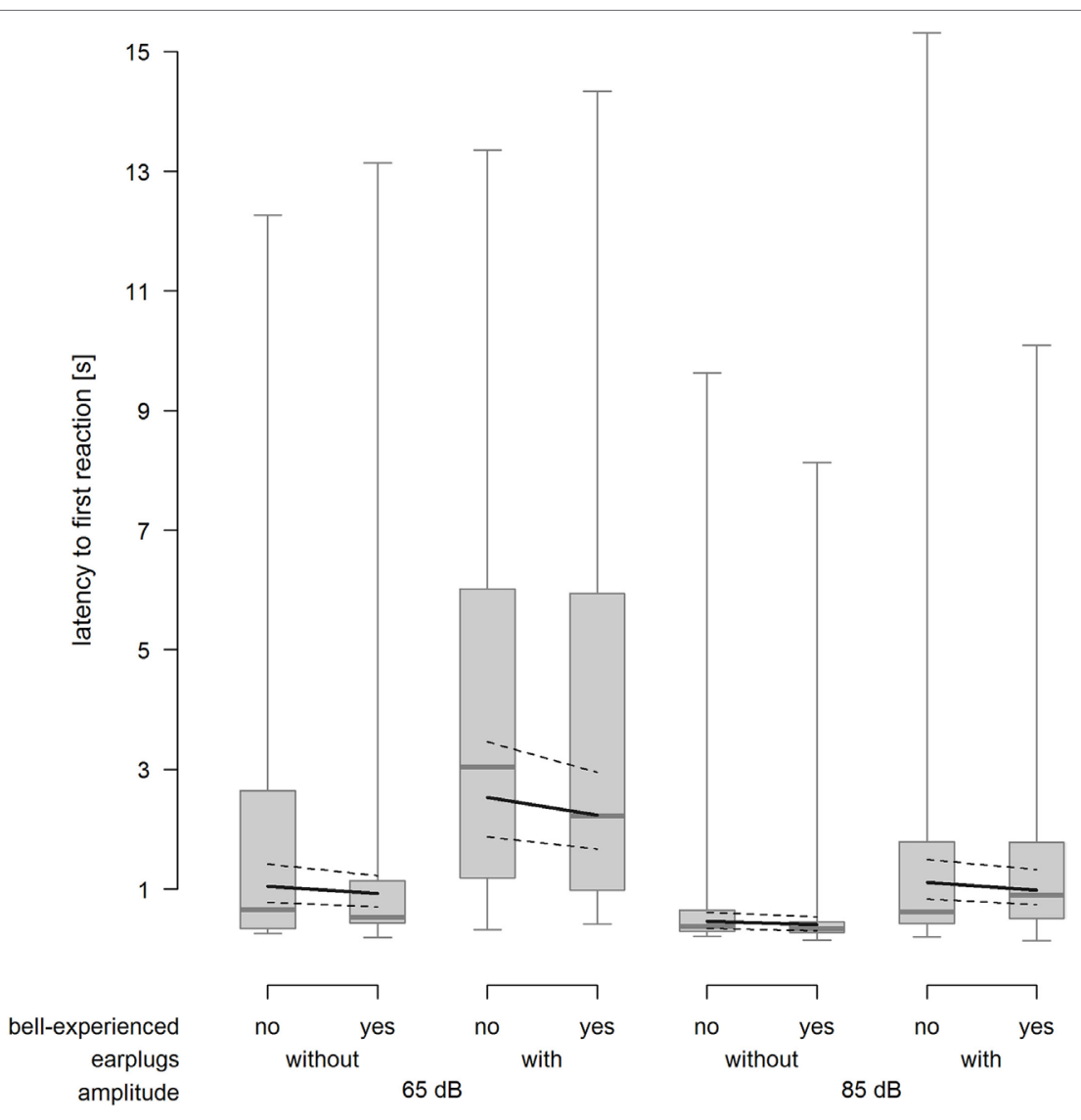

FIGURE 4 | Latency to the first reaction $15 \mathrm{~s}$ after onset of the playback stimulus depending on bell-experienced (no, yes), earplugs (without, with) and amplitude $(65,85 \mathrm{~dB})$. Descriptive data are presented as box plots indicating observed median, first and third quartiles, and absolute range of data. Solid lines show the model estimation and dotted lines show the lower and upper 95\% confidence intervals. 


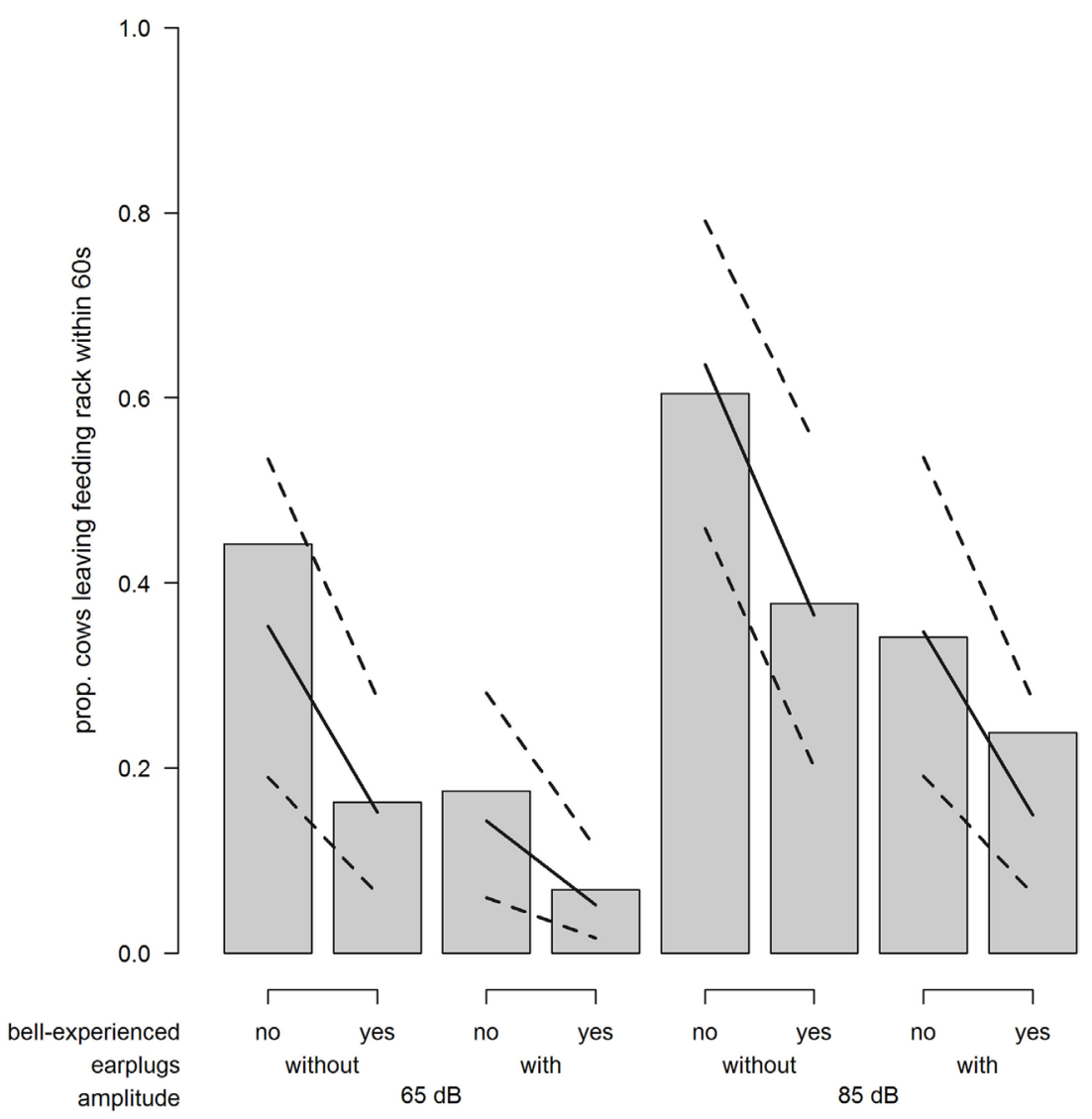

FIGURE 5 | Avoidance. Proportion of cows leaving the feeding rack within $60 \mathrm{~s}$ after playback depending on bell-experienced (no, yes), earplugs (without, with), and amplitude $(65,85 \mathrm{~dB})$. Solid lines show the model estimation, and dotted lines show the lower and upper $95 \%$ confidence intervals.

Figure 6C). Again, no effect of bell experience was detectable $\left(F_{1,60.0}=0.07 ; P=0.797\right)$.

\section{DISCUSSION}

The experimental setting in this study allowed an assessment of the cows' reactions to acoustic stimuli as both amplitude and earplugs affected all outcome variables in a meaningful way. However, none of the cows seemed to have severe hearing impairment as earplugs diminished the reactions of the cows to the acoustic stimuli. Overall, the cows responded to the $85-\mathrm{dB}$ stimulus stronger than to the $65-\mathrm{dB}$ stimulus. Bell experience and earplugs reduced avoidance of the noise stimulus. The high-amplitude stimulus $(85 \mathrm{~dB})$ triggered a shorter latency to the first reaction and increased heart rate and avoidance than the low-amplitude stimulus $(65 \mathrm{~dB})$. With earplugs, the latency to the first reaction was longer, and the cows showed less avoidance of the sound stimulus. However, bell experience had no effect on the latency to the first reaction.

Our results correspond to previous studies that found noises with higher amplitudes (e.g., $>85 \mathrm{~dB}$ ) evoke stronger behavioral reactions than noises with lower amplitudes in farm animals. When exposed to a playback of background noise recorded in milking parlors and broadcast at $85 \mathrm{~dB}$ in a raceway, heifers showed faster transit times, indicating an escape reaction (55). Heifers exposed to playbacks of people shouting $(86 \mathrm{~dB})$ and metal-on-metal clanging $(85 \mathrm{~dB})$ moved more often compared to no noise (56). Talling et al. (57) and Geverink et al. (58) found aberrant behavior when sound levels were up to $85 \mathrm{~dB}$ in pigs. Further, pregnant ewes that were exposed to noises with amplitudes increasing from 45 to $95 \mathrm{~dB}$ reduced their feeding time and increased the time spent inactive (59). MacKenzie et al. (60) found that hens showed avoidance to high-intensity noises (90-110 dB). Consequently, in this study, a shorter latency to the first reaction and increased avoidance indicate that cows perceived the acoustic stimuli as aversive.

The amplitudes of cowbells that are traditionally used on Alpine pastures vary between 90 and $113 \mathrm{~dB}$ (1). However, we did not measure the amplitudes of the bells that the experienced cows were wearing during pasture season. It is likely that there were differences in the amplitudes of the bells worn by the experienced cows. If so, this might explain the wide variability of responses observed in the experienced cows to a certain extent.

Furthermore, the increased heart rate during the $85-\mathrm{dB}$ stimulus without earplugs corresponds to previous studies that found noises with higher amplitudes evoking stronger cardiac reactions than noises with lower amplitudes in pigs and humans. Talling et al. (57) found that pigs had a higher heart rate when 


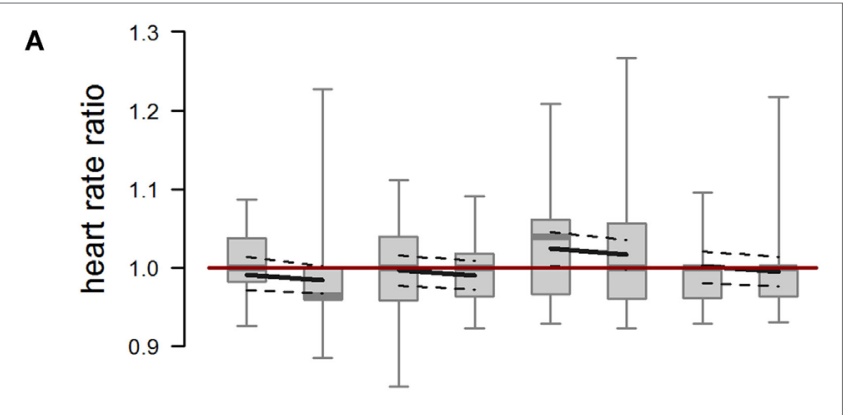

B

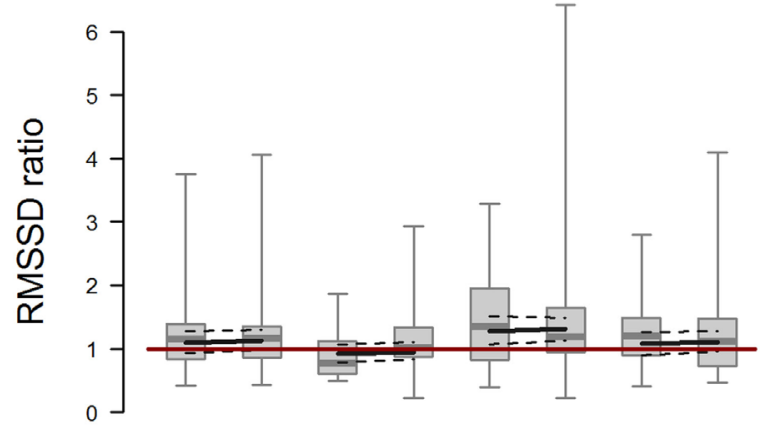

C

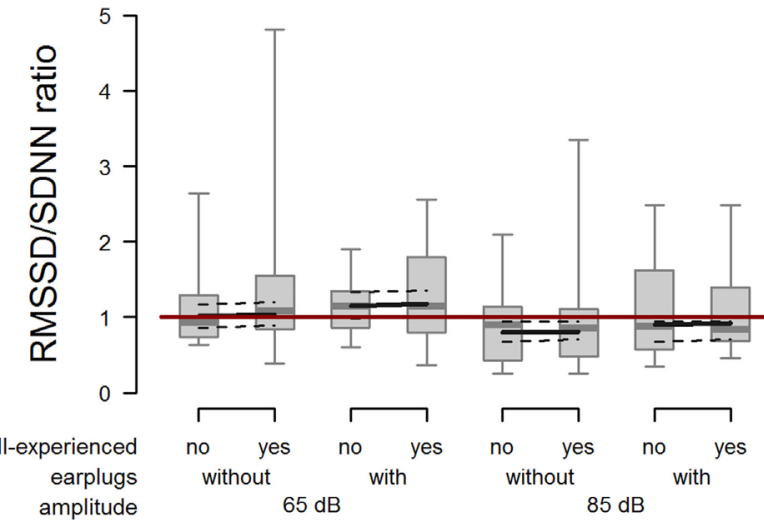

FIGURE 6 | Heart rate, root mean square of successive difference (RMSSD), and RMSSD/standard deviation of heartbeats (SDNN). Ratio of (A) heart rate, (B) RMSSD, and (C) RMSSD/SDNN between playback and reference situation depending on bell-experienced (no, yes), earplugs (without, with), and amplitude $(65,85 \mathrm{~dB})$. Descriptive data are presented as box plots indicating observed median, first and third quartiles, and absolute range of data. Solid lines show the model estimation, and dotted lines the lower and upper $95 \%$ confidence intervals. The dark red line represents the ratio value in case of identical values during trial and reference.

exposed to very loud ( $97 \mathrm{~dB}$ ) compared with loud ( $85 \mathrm{~dB}$ ) stimuli. In addition, a sudden loud sound $(110 \mathrm{~dB}, 1-20 \mathrm{kHz}, 0.15 \mathrm{~s})$ evoked an immediate increase of heart rate in humans (29). In our study, changes in heart rate, RMSSD, and the ratio between RMSSD and SDNN were rather small (i.e., ratios varied little and were close to 1), thus the cardiac reaction following the playback has to be interpreted with caution. However, Désiré et al. (61, 62) showed that the sudden appearance of an object elicited an increase in heart rate in lambs most likely due to enhanced sympathetic activity, i.e., increased arousal. In addition, the exposure to a novel object elicited an increase in RMSSD, indicating an increased parasympathetic activity. In the current study, heart rate after the playback at $85 \mathrm{~dB}$ was increased most likely due to enhanced sympathetic activity, and RMSSD ratio was increased due to an increased parasympathetic activity. At the same time, RMSSD/SDNN ratio was reduced, indicating a stronger activation of the sympathetic branch, overall. Consequently, the pink noise stimulus might have been both sudden and novel $(31,63)$.

Cows avoided the playback stimulus less when wearing earplugs, or when their farm of origin used bells during the pasture season (bell experienced), which may reflect an altered acoustic perception of the playback stimulus due to routine bell exposure. Furthermore, only cows from farms that did not use bells for their cows did not start feeding again after being exposed to the playback. This may indicate that the playback was perceived as aversive by these cows. Although the experimental setting of our study did not allow us to conclusively assess the hearing capacity of the cows, a reduced reactivity to the acoustic stimuli due to hearing impairment of bell-experienced cows cannot be excluded completely. In humans, dogs and mice hearing loss has been shown to occur after they were exposed to noise with amplitudes similar to those of cowbells. Further, exposure time in these studies was similar to the time cows are exposed to bells while on pasture $(3-5,33)$. However, given the effect of the earplugs and the fact that all cows in our study showed a reaction to the playback in at least one trial, none of them seemed to have a severe hearing impairment.

Considering the experimental setting in retrospect, the pink noise stimulus might not have been ideal to assess the full hearing capacity of cows. Given that cows can hear sounds between $23 \mathrm{~Hz}$ and $35 \mathrm{kHz}(10)$, a high-pass filter that blocks LFs and passes HFs (64), or a stimulus that contains only higher frequencies might be more suitable to test cows' hearing capacity in future studies since hearing impairment is associated with reduced sensitivity to HFs. In addition, the $85-\mathrm{dB}$ stimulus used in our study might have been too loud to detect subtle differences in hearing capacities. On the other hand, the amplitude used to elicit an acoustic startle response was more than $80 \mathrm{~dB}$ in other studies $(12,18$, $19,29,31)$. Thus, inferring information about hearing capacity from a latency to the first reaction to an acoustic stimulus as a proxy for the induction of a startle response might partly be misleading when using a high-amplitude stimulus, and other behavioral indicators have to be found. Furthermore, the studies mentioned above $(3-5,33)$ used standardized clinical hearing tests (BAEP and ABR). BAEP are bioelectric waves that can be recorded within $10 \mathrm{~ms}$ after an auditory stimulus and are used to assess auditory function (65). Due to the influence of excessive muscle movements on the measurement, it is necessary for the subject to be motionless during the procedure (37). Clinically, therefore, sedation is needed when measuring BAEP in young children or animals. Accordingly, BAEP measurements need to be conducted in a veterinary hospital rather than on-farm to be able to monitor the animals more closely.

Altogether, we could not clinically assess the hearing capacity of bell-experienced cows. Nevertheless, our indicators showed that routine bell exposure led to a mitigation of the behavioral response to a novel acoustic stimulus. Overall, the cows responded 
to the $85-\mathrm{dB}$ stimulus stronger than to the $65-\mathrm{dB}$ stimulus and using cowbells with lower amplitudes might be advantageous.

\section{CONCLUSION}

Our results demonstrated that acute exposure to the $85-\mathrm{dB}$ pink noise stimulus triggered increased arousal and avoidance compared with the $65-\mathrm{dB}$ stimulus. Heart rate and heart rate variability indicated increased sympathetic activation during the exposure to $85 \mathrm{~dB}$ compared with $65 \mathrm{~dB}$. Bell experience and wearing earplugs led to a generally decreased avoidance of the stimulus compared with bell-inexperienced cows and with cows not wearing earplugs. This may reflect an altered acoustic perception of the playback stimulus due to noise habituation, a low-reactive animal in general, or impaired hearing capacity when routinely exposed to bells.

\section{ETHICS STATEMENT}

Ethical approval to conduct the study was obtained from the Zurich Cantonal Veterinary Office, Switzerland (approval No. 77/2012).

\section{REFERENCES}

1. Johns J, Patt A, Hillmann E. Do bells affect behaviour and heart rate variability in grazing dairy cows? PLoS One (2015) 10:e0131632. doi:10.1371/journal. pone.0131632

2. Johns J, Patt A, Hillmann E. Effects of sounds of different quality on the behaviour and heart beat parameters of goats. Appl Anim Behav Sci (2015) 165:72-80. doi:10.1016/j.applanim.2015.02.005

3. Scheifele P, Martin D, Clark JG, Kemper D, Wells J. Effect of kennel noise on hearing in dogs. Am J Vet Res (2012) 73:482-9. doi:10.2460/ajvr. 73.4.482

4. Chuang S, Lei S, Xuejun J, Shiming Y, Ke L. Effects of moderate noise exposure on hearing function in C57BL/6J mice. J Otol (2014) 9:81-5. doi:10.1016/ S1672-2930(14)50019-0

5. Park SN, Back SA, Park KH, Seo JH, Noh HI, Akil O, et al. Comparison of functional and morphologic characteristics of mice models of noiseinduced hearing loss. Auris Nasus Larynx (2013) 40:11-7. doi:10.1016/j. anl.2011.11.008

6. Miller MH, Schein JD. Hearing Disorders Handbook. San Diego, CA: Plural Publishing, Inc (2008). 275 p.

7. Fay RR. Hearing in Vertebrates: A Psychophysics Databook. Winnetka, IL: Hill-Fay Associates (1988).

8. Strain GM, Myers LJ. Hearing and equilibrium. In: Reece WO, editor. Dukes's Physiology of Domestic Animals. Ithaca, NY: Cornell University Press (2004). p. 852-64.

9. Fay RR, Popper AN. Evolution of hearing in vertebrates: the inner ears and processing. Hear Res (2000) 149:1-10. doi:10.1016/S0378-5955(00)00168-4

10. Heffner RS, Heffner HE. Hearing in large mammals: horses (Equus caballus) and cattle (Bos taurus). Behav Neurosci (1983) 97:299-309. doi:10.1037/0735-7044.97.2.299

11. Heffner RS, Heffner HE. Hearing in domestic pigs (Sus scrofa) and goats (Capra hircus). Hear Res (1990) 48:231-40. doi:10.1016/0378-5955(90)90063-U

12. Blaszczyk JW, Tajchert K. Effect of acoustic stimulus characteristics on the startle response in hooded rats. Acta Neurobiol Exp (1997) 57:315-21.

13. Lanier JL, Grandin T, Green RD, Avery D, McGee K. The relationship between reaction to sudden, intermittent movements and sounds and temperament. J Anim Sci (2000) 78:1467-74. doi:10.2527/2000.7861467x

14. Clements M, Kelly JB. Directional responses by kittens to an auditory stimulus. Dev Psychobiol (1978) 11:505-11. doi:10.1002/dev.420110514

\section{AUTHOR CONTRIBUTIONS}

Study design: JJ and EH. Data collection: JJ, SM, and AP. Data analysis: JJ and EH. Manuscript drafting: JJ, AP, and EH. Critical revisions of the manuscript: SM, AP, and EH. Final approval: JJ, $\mathrm{SM}, \mathrm{AP}$, and $\mathrm{EH}$.

\section{ACKNOWLEDGMENTS}

We thank all farmers for their participation in this study, their openness and trust toward us, many informative discussions, and their hospitality. We also thank Simon Peter Luzi for his assistance with data collection and analysis as well as Karin Scheuss and Sarina Fetscher for analyzing the video recordings. We are grateful to PD Dr. Lorenz Gygax for his support during the statistical analyses.

\section{FUNDING}

The project was funded by budget funds of ETH Zurich and Felsentorstiftung.

15. Braff D, Stone C, Callaway E, Geyer M, Glick I, Bali L. Prestimulus effects on human startle reflex in normals and schizophrenics. Psychophysiology (1978) 15:339-43. doi:10.1111/j.1469-8986.1978.tb01390.x

16. Pryor GT, Rebert CS, Howd RA. Hearing loss in rats caused by inhalation of mixed xylenes and styrene. JAppl Toxicol (1987) 7:55-61. doi:10.1002/ jat.2550070110

17. Knudsen FR, Enger PS, Sand O. Avoidance responses to low frequency sound in downstream migrating Atlantic salmon smolt, Salmo salar. J Fish Biol (1994) 45:227-33. doi:10.1111/j.1095-8649.1994.tb01302.x

18. Pilz PK, Schnitzler HU, Menne D. Acoustic startle threshold of the albino rat (Rattus norvegius). JComp Psychol (1987) 101:67-72. doi:10.1037/0735-7036.101.1.67

19. Valsamis B, Schmid S. Habituation and prepulse inhibition of acoustic startle in rodents. J Vis Exp (2011) 55:e3446. doi:10.3791/3446

20. Cassella JV, Harty TP, Davis M. Fear conditioning, pre-pulse inhibition and drug modulation of a short latency startle response measured electromyographically from neck muscles in the rat. Physiol Behav (1986) 36:1187-91. doi:10.1016/0031-9384(86)90499-3

21. Pilz PK, Caesar M, Ostwald J. Comparative threshold studies of the acoustic pinna, jaw and startle reflex in the rat. Physiol Behav (1988) 43:411-5. doi:10.1016/0031-9384(88)90112-6

22. Koch M, Schnitzler HU. The acoustic startle response in rats - circuits mediating evocation, inhibition and potentiation. Behav Brain Res (1997) 89:35-49. doi:10.1016/S0166-4328(97)02296-1

23. Neumann DL, Waters AM. The use of an unpleasant sound as anconditional stimulus in a human aversive Pavlovian conditioning procedure. Biol Psychol (2006) 73:175-85. doi:10.1016/j.biopsycho.2006.03.004

24. Ehret G. Development of hearing and response behavior to sound stimuli: behavioral studies. In: Romand R, Varela-Nieto I, editors. Development of Auditory and Vestibular Systems. Oxford, UK: Academic Press (1983).p. 211-37.

25. Rushen J. Using aversion learning techniques to assess the mental state, suffering, and welfare of farm animals. JAnim Sci (1996) 74:1990-5. doi: $10.2527 / 1996.7481990 x$

26. Talling JC, Waran NK, Wathes CM, Lines JA. Sound avoidance by domestic pigs depends upon characteristics of the signal. Appl Anim Behav Sci (1998) 58:255-66. doi:10.1016/S0168-1591(97)00142-1

27. Arnold NA, Ng KT, Jongman EC, Hernsworth PH. Avoidance of taperecorded milking facility noise by dairy heifers in a Y maze choice task. Appl Anim Behav Sci (2008) 109:201-10. doi:10.1016/j.applanim.2007.02.002 
28. Gomez P, Danuser B. Affective and physiological responses to environmental noises and music. Int J Psychophysiol (2004) 53:91-103. doi:10.1016/j. ijpsycho.2004.02.002

29. Holand S, Girard A, Laude D, Meyer-Bisch C, Elghozi JL. Effects of an auditory startle stimulus on blood pressure and heart rate in humans. J Hypertens (1999) 17:1893-7. doi:10.1097/00004872-199917121-00018

30. Carter N, Henderson R, Lal S, Hart M, Booth S, Hunyor S. Cardiovascular and autonomic response to environmental noise during sleep in night shift workers. Sleep (2002) 25:457-64. doi:10.1093/sleep/25.4.444

31. Lee GS, Chen ML, Wang GY. Evoked response of heart rate variability using short-duration white noise. Auton Neurosci (2010) 155:94-7. doi:10.1016/j. autneu.2009.12.008

32. Holgers KM, Pettersson B. Noise exposure and subjective hearing symptoms among school children in Sweden. Noise Health (2005) 7:27-37. doi:10.4103/1463-1741.31635

33. Daniel E. Noise and hearing loss: a review. J Sch Health (2007) 77:225-31. doi:10.1111/j.1746-1561.2007.00197.x

34. Viallet G, Sgard F, Laville F, Nélisse H. Investigation of the variability in earplugs sound attenuation measurements using a finite element model. Appl Acoust (2015) 89:333-44. doi:10.1016/j.apacoust.2014.10.007

35. MacFarlane PD, Mosing M, Burford J. Preliminary investigation into the effects of earplugs on sound transmission in the equine ear. Pferdeheilkunde (2010) 26:199-203. doi:10.21836/PEM20100213

36. Strain GM, Olcott BM, Thompson DR, Graham MC. Brainstem auditory-evoked potentials in Holstein cows. J Vet Intern Med (1989) 3:144-8. doi:10.1111/j.1939-1676.1989.tb03090.x

37. Arai S, Matsui Y. Brainstem auditory evoked potentials in Japanese Black and Holstein cattle. J Vet Med Sci (2008) 70:1139-42. doi:10.1292/jvms.70.1139

38. Arai S, Matsui Y, Fukuda S, Okada H, Onoe S. Brainstem auditory evoked potentials in experimentally-induced bovine spongiform encephalopathy. Res Vet Sci (2009) 87:111-4. doi:10.1016/j.rvsc.2008.10.019

39. Manci KM, Gladwin DN, Villella R, Cavendish MG. Effects of Aircraft Noise and Sonic Booms on Domestic Animals and Wildlife: A Literature Synthesis. Ft. Collins, CO: U.S. Fish and Wildlife Service National Ecology Research Center (1988). 88 p.

40. Zhou J, Liu D, Li X, Ma J, Zhang J, Fang J. Pink noise: effect on complexity synchronization of brain activity and sleep consolidation. J Theor Biol (2012) 306:68-72. doi:10.1016/j.jtbi.2012.04.006

41. Langbein J, Nürnberg G, Manteuffel G. Visual discrimination learning in dwarf goats and associated changes in heart rate and heart rate variability. Physiol Behav (2004) 82:601-9. doi:10.1016/j.physbeh.2004.05.007

42. von Borell E, Langbein J, Després G, Hansen S, Leterrier C, Marchant-Forde J, et al. Heart rate variability as a measure of autonomic regulation of cardiac activity for assessing stress and welfare in farm animals - a review. Physiol Behav (2007) 92:293-316. doi:10.1016/j.physbeh.2007.01.007

43. R Core Team. R: A Language and Environment for Statistical Computing. Vienna, Austria: R Foundation for Statistical Computing (2016). Available from: https://www.r-project.org/

44. Task Force of the European Society of Cardiology and the North American Society of Pacing and Electrophysiology. Heart rate variability: standards of measurement, physiological interpretation, and clinical use. Eur Heart $J$ (1996) 17:354-81. doi:10.1093/oxfordjournals.eurheartj.a014868

45. Kleiger RE, Stein PK, Bosner MS, Rottman JN. Time domain measurements of heart rate variability. In: Malik M, Camm AJ, editors. Heart Rate Variability. Armonk, NY: Futura Publishing Co., Inc (1995). p. 195-204.

46. Hagen K, Langbein J, Schmied C, Lexer D, Waiblinger S. Heart rate variability in dairy cows-influences of breed and milking system. Physiol Behav (2005) 85:195-204. doi:10.1016/j.physbeh.2005.03.019

47. Patt A, Gygax L, Wechsler B, Hillmann E, Langbein J, Keil NM. Context specificity of the ANS stress response during two regrouping experiments in goats. Front Vet Sci (2016) 3:58. doi:10.3389/fvets.2016.00058

48. Kuhne F, Hoessler JC, Struwe R. Behavioral and cardiac responses by dogs to physical human-dog contact. J Vet Behav (2014) 9:93-7. doi:10.1016/j. jveb.2014.02.006
49. Zebunke M, Langbein J, Manteuffel G, Puppe B. Autonomic reactions indicating positive affect during acoustic reward learning in domestic pigs. Anim Behav (2011) 81:481-9. doi:10.1016/j.anbehav.2010.11.023

50. Gygax L, Neuffer I, Kaufmann C, Hauser R, Wechsler B. Restlessness behaviour, heart rate and heart rate variability of dairy cows milked in two types of automatic milking systems and auto-tandem milking parlours. Appl Anim Behav Sci (2008) 109:167-79. doi:10.1016/j.applanim.2007.03.010

51. Yue Y, Lin L. Statistical Tools for Measuring Agreement. (2015). Available from: https://CRAN.R-project.org/package=agRee

52. Bates D, Maechler M, Bolker B, Walker S. Lme4: Linear Mixed-Effects Models Using Eigen and S4. (2015). Available from: https://CRAN.R-project.org/ package $=\operatorname{lme} 4$

53. Christensen RHB. Ordinal - Regression Models for Ordinal Data. (2015). Available from: https://cran.r-project.org/web/packages/ordinal/index.html

54. Szumilas M. Explaining odds ratios. J Can Acad Child Adolesc Psychiatry (2010) 19:227-9. Correction in: Erratum: J Can Acad Child Adolesc Psychiatry (2015) 24:58.

55. Arnold NA, Ng KT, Jongman EC, Hemsworth PH. The behavioural and physiological responses of dairy heifers to tape-recorded milking facility noise with and without a pre-treatment adaptation phase. Appl Anim Behav Sci (2007) 106:13-25. doi:10.1016/j.applanim.2006.07.004

56. Waynert DF, Stookey JM, Schwartzkopf-Genswein KS, Watts JM, Waltz CS. The response of beef cattle to noise during handling. Appl Anim Behav Sci (1999) 62:27-42. doi:10.1016/S0168-1591(98)00211-1

57. Talling JC, Waran NK, Wathes CM, Lines JA. Behavioural and physiological responses of pigs to sound. Appl Anim Behav Sci (1996) 48:187-201. doi:10.1016/0168-1591(96)01029-5

58. Geverink NA, Bühnemann A, van de Burgwal JA, Lambooij E, Blokhuis HJ, Wiegant VM. Responses of slaughter pigs to transport and lairage sounds. Physiol Behav (1998) 63:667-73. doi:10.1016/S0031-9384(97)00513-1

59. Quaranta A, Sevi A, Nardomarino A, Colella GE, Casamassima D. Effects of graded noise levels on behavior, physiology and production performance of intensively managed lambs. Ital J Anim Sci (2002) 1:217-27. doi:10.4081/ijas.2002.217

60. MacKenzie JG, Foster TM, Temple W. Sound avoidance by hens. Behav Processes (1993) 30:143-56. doi:10.1016/0376-6357(93)90004-B

61. Désiré L, Veissier I, Després G, Boissy A. On the way to assess emotions in animals: do lambs (Ovis aries) evaluate an event through suddenness, novelty or unpredictability? J Comp Psychol (2004) 118:363-74. doi:10.1037/07357036.118.4.363

62. Désiré L, Veissier I, Després G, Delval E, Toporenko G, Boissy A. Appraisal process in sheep (Ovis aries): interactive effect of suddenness and unfamiliarity on cardiac and behavioral responses. J Comp Psychol (2006) 120:280-7. doi:10.1037/0735-7036.120.3.280

63. Hainsworth R. The control and physiological importance of heart rate. In: Malik M, Camm AJ, editors. Heart Rate Variability. Armonk, NY: Futura Publishing Co., Inc (1995). p. 3-19.

64. Johnson K. Basic acoustics and acoustic filters. In: Johnson K, editor. Acoustic and Auditory Phonetics. West Sussex, UK: John Wiley \& Sons, Inc (2012). p. 3-18.

65. Chiappa KH. Brain stem auditory evoked potentials: methodology. In: Chiappa KH, editor. Evoked Potentials in Clinical Medicine. Philadelphia, NY: Lippincott-Raven Publishers (1997). p. 157-97.

Conflict of Interest Statement: The authors declare that the research was conducted in the absence of any commercial or financial relationships that could be construed as a potential conflict of interest.

Copyright (C) 2017 Johns, Masneuf, Patt and Hillmann. This is an open-access article distributed under the terms of the Creative Commons Attribution License (CC BY). The use, distribution or reproduction in other forums is permitted, provided the original author(s) or licensor are credited and that the original publication in this journal is cited, in accordance with accepted academic practice. No use, distribution or reproduction is permitted which does not comply with these terms. 